\section{Preface}

\section{Check for updates}

\section{OPEN ACCESS}

(c) 2019 Korean Society of Global Health.

This is an Open Access article distributed under the terms of the Creative Commons Attribution Non-Commercial License (https:// creativecommons.org/licenses/by-nc/4.0/) which permits unrestricted non-commercial use, distribution, and reproduction in any medium, provided the original work is properly cited.

ORCID IDs

Sung-Tae Hong (1D

https://orcid.org/0000-0002-0300-1944

\title{
Journal of Global Health Science, new platform of global health research
}

\section{Sung-Tae Hong $(\mathbb{D}$}

President of the Korean Society of Global Health

Global health is a new discipline of medical science that is nonetheless rapidly expanding its reach. Many Korean overseas development assistance and non-governmental global health projects are operating around the world owing to expanding government commitment to funding relevant budgets. Most of these projects are operational research initiatives that are implemented at the community level. Although project findings are typically documented in reports for the funders, key results are often unpublished in scholarly journals. Yet, publication in scholarly journals is essential to sharing global health operational research findings with other health professionals and is also essential to ensuring that lessons learned contribute to a permanent archive of scientific knowledge.

In this context, the launching of the Journal of Global Health Science is a substantial contribution to the work of global health professionals and researchers in Korea. In a sense, all health workers are operational researchers. Communities served by health projects are diverse and continuously changing with passing time. Therefore, health initiatives that based on similar designs and goals may produce different outcomes in contrasting localities or in contexts where durations and timing of observation differ. Contrasting contexts therefore require the process of scientific investigation, review and discussion that scholarly journals provide. This central goal of scientific publication is critical to the effective planning and design of projects wherever they may be conducted in the future.

The Journal of Global Health Science should be a platform of scientific communication between global health professionals and researchers throughout the world, as well as in Korea. The Editor of the journal, Dr. Juhwan Oh, will contribute to this core role of the Korean global health scientific community by editing and publishing the journal. All global health professionals are open to participate in this new global health endeavor as authors, reviewers and readers. And in the process, we can work together to accelerate progress in global health development. 